\title{
The Association between Attention Deficit/Hyperactivity Disorder Symptoms and the Number of Suicide Attempts among Male Young Adults with Unipolar and Bipolar Depression
}

\author{
Chan-Mo Yang and Bung-Nyun Kim \\ Division of Child and Adolescent Psychiatry, Department of Psychiatry, Seoul National University Hospital, Seoul, Korea
}

\begin{abstract}
Objectives: Mood disorder is highly comorbid with attention deficit/hyperactivity disorder (ADHD), and comorbid ADHD symptoms are associated with suicide risk. The aim of this study was to examine the association between comorbid ADHD symptoms and the number of suicide attempts among patients with unipolar and bipolar depression.

Methods: In this cross-sectional study, 100 patients with either unipolar or bipolar depression constituted the final sample. Pearson's correlation and multiple regression analyses were conducted to examine the association between comorbid ADHD symptoms and suicide risk.

Results: Among patients with bipolar depression, the number of suicide attempts was significantly correlated with ADHD symptoms $(\mathrm{r}=0.324, \mathrm{p}<0.01)$. ADHD symptoms significantly predicted the number of suicide attempts $(\beta=0.249, \mathrm{p}<0.05)$.

Conclusion: Our findings underscore the importance of screening and assessing ADHD symptoms in male young adults with depressive disorders.
\end{abstract}

Key Words: Attention deficit/hyperactivity disorder; Bipolar disorder; Depression; Suicide; Young adulthood.

Received: March 6, 2020 / Revised: March 14, 2020 / Accepted: March 18, 2020

Address for correspondence: Bung-Nyun Kim, Division of Child and Adolescent Psychiatry, Department of Psychiatry, Seoul National University College of Medicine, 101 Daehak-ro, Jongno-gu, Seoul 03080, Korea

Tel: +82-2-2072-3647, Fax: +82-2-747-2471, E-mail: kbn1@snu.ac.kr

\section{INTRODUCTION}

According to the results of the World Health Organization Mental Health Surveys, the average prevalence of attention deficit/hyperactivity disorder (ADHD) is $2.2 \%$ among children, and $57 \%$ of such children continue to experience the symptoms of ADHD during adulthood [1]. Faraone et al. [2] found that $62 \%$ of children diagnosed with ADHD are symptomatic, but only $19 \%$ of them meet the diagnostic criteria for ADHD at the age of 25 years. Past study has also found that ADHD affects $4.4 \%$ of adults within the general population [3]. However, adult ADHD is likely to be underdiagnosed [4], even though the health and psychosocial burden associated with ADHD is similar to that of other mental disorders [5].

ADHD has profound effects on daily functioning. If left untreated during childhood or adulthood, ADHD symptoms can lead to behavioral, emotional, social, academic, and voca-

This is an Open Access article distributed under the terms of the Creative Commons Attribution Non-Commercial License (https://creativecommons.org/licenses/by-nc/4.0) which permits unrestricted non-commercial use, distribution, and reproduction in any medium, provided the original work is properly cited. tional problems [6,7]. Moreover, if ADHD is associated with comorbid disorders without treatment, it may lead to greater functional impairment [4]. It has been reported that the number of psychiatric comorbidities is higher among adults with ADHD than among those without ADHD [8].

Mood disorder is highly comorbid with ADHD. According to the results of a representative comorbidity survey in the United States, $38.3 \%$ of patients with ADHD have a mood disorder [3]. Retrospective studies on adult ADHD have found that the prevalence rate of depression ranges from $35 \%$ to $50 \%$ $[3,9]$. Clinical outcomes tend to be poor when both the conditions are present in an individual [10]. Indeed, depression tends to be more severe when it is comorbid with ADHD and past findings suggest that it is associated with greater functional impairment and higher rates of suicidality [11]. In addition, patients with both ADHD and bipolar disorder (BPD) tends to be more severe in patients who also have ADHD than in those without ADHD [12]. More importantly, comorbid ADHD symptoms have been found to be associated with greater risk of serious suicide and functional impairment 
[13]. An adult psychiatric morbidity survey found that there is a positive association between the severity of adult ADHD symptoms and suicide attempts during one's lifetime or within the past 12 months [14]. ADHD rates tend to be higher among suicide attempters than among nonattempters, and the odds ratios range from 2.6 to 7.3 [15].

The results of a few studies suggest that there is an association between ADHD symptoms and suicide risk in mood disorders; however, these results have not been consistently replicated among clinical samples. In addition, to the best of our knowledge, no past study has examined this association among patients with bipolar depression. Therefore, the aim of this study was to examine the association between comorbid ADHD symptoms and suicide risk among patients with unipolar and bipolar depression.

\section{METHODS}

\section{Participants}

In this cross-sectional study, those who visited the Navy Medical Center psychiatric outpatient clinic for the first time between May 2017 and February 2018 were eligible for inclusion in the sample. Patients who were experiencing a major depressive episode as per the criteria outlined in the Diagnostic and Statistical Manual of Mental Disorders (DSM-IV-TR) [18] were included, and they were classified into two groups based on whether they had unipolar or bipolar depression. We excluded those who had a history of manic or mixed episodes. Patients with bipolar depression were screened using the Mood Disorder Questionnaire (MDQ) [16] and diagnosed with either BPD II or BPD not otherwise specified (BPD-NOS) currently experiencing depressive episode. Patients who had childhood ADHD symptoms and obtained positive results on the screener version of the Adult ADHD Self-Report Scale (ASRS) [17] were considered to have comorbid ADHD symptoms. A total of 114 patients met the sample inclusion criteria, but 14 patients were excluded because of missing data. Finally, the data of 100 patients were analyzed. Informed consent was obtained from all the participants prior to the administration of the assessments. This study was approved by the Institutional Review Boards (IRB) of the Armed Forces Medical Command in Korea (AFMC-18-IRB-006).

\section{Measures}

Self-report questionnaires were used to collect information about sociodemographic characteristics and clinical symptom-related variables. The following variables were assessed: age, sex, family structure, perceived socioeconomic status (SES), body mass index (BMI), educational status, and number of past suicide attempts.

\section{Patient Health Questionnaire-9}

In this study, the Korean version of the Patient Health Questionnaire-9 (PHQ-9) [18], which is a reliable and valid 9-question assessment, was used to measure depressive symptom severity. The questions have been developed based on the DSM-IV criteria for depression. Responses to each item are recorded on a scale that ranges from 0 (not at all) to 3 (nearly every day). The overall Cronbach's alpha for the Korean version was 0.88 .

\section{Mood Disorder Questionnaire}

To screen for bipolar spectrum disorder, the Korean versions of the MDQ [16] were used. The MDQ is a self-report screening tool that consists of three sections [19]. The first section consists of 13 items, which assess previous hypomanic symptoms. The second section consists of one item, which assesses whether the symptoms recorded in the first section have occurred simultaneously. The third section consists of one statement, which pertains to the influence of related symptoms. To define MDQ positivity, we referred to the original cutoff score that has been recommended by Hirschfeld (seven or more symptoms reported in the first section, occurring simultaneously, and resulting in at least moderate impairment).

\section{Screener version of the adult ASRS}

The participants also completed the Korean screener version of the Adult ASRS [20]. The ASRS items assess the DSMIV-TR Criteria A symptoms. In contrast, the screener consists of only six ASRS items, which have the strongest psychometric properties. Patients who reported experiencing at least four of the six symptoms (i.e., six items of the ASRS Screener) frequently were considered to have ADHD symptoms.

\section{Conners' Adult ADHD Rating Scale-Korean short version}

Conners et al. [21] developed the Conners' Adult ADHD Rating Scale (CAARS). Subsequently, it was modified and translated into Korean [i.e., Conners' Adult ADHD Rating Scale-Korean short version (CAARSK-SV)]. The validity and reliability of this measure of ADHD were established using a sample of 505 Korean university students [22]. This short version is undergirded by a four-factor structure, which is identical to that of CAARS. Responses to each item are recorded on a frequency scale that ranges from 1 (never) to 4 (very often). A higher score indicates higher character of the given question.

\section{Mini International Neuropsychiatric Interview Suicidal Scale}

The Mini International Neuropsychiatric Interview (MINI) Suicidal Scale is a subscale of the MINI [23]. Jointly developed and validated by psychiatrists and clinicians in the United 
States and Europe, it is a short structured diagnostic interview guide that is used to psychiatric disorders as per the DSM-IVTR and International Classification of Mental and Behavioral Disorders (10th revision; ICD-10). The short version of the MINI Suicidal Scale consists of six yes-no items. Items 1-5 assess whether an event has occurred during the past month, whereas item 6 assesses the lifetime occurrence of the event. Each item score is weighted based on the estimated contribution to the risk level. The total scores yielded by the short version can range from 0 to 33 points.

\section{Statistical analyses}

Chi-squared analysis and independent-samples t-test were used to compare the sociodemographic and psychological characteristics of those with unipolar and bipolar depression. Pearson's correlation analysis was conducted to examine the association between the number of suicide attempts and other variables, including psychological factors. Multiple hierarchical regression analysis was conducted to examine the effect of the independent variables on the number of suicide attempts. A p-value $<0.05$ was considered to be statistically significant across all the analyses. Statistical Package for the Social Sciences (SPSS, version 23.0; IBM Corp., Armonk,
NY, USA) was used to conduct the aforementioned analyses.

\section{RESULTS}

All the participants were men. Thirty-seven participants were diagnosed with major depressive disorder. Sixty-three patients who met the DSM-IV-TR criteria for BPD-NOS or BPD II constituted the BPD group. Differences in the sociodemographic and clinical characteristics of patients with unipolar and bipolar depression were not significant (Table 1 and 2).

The severity of adult ADHD symptoms was significantly correlated with suicide risk, which was assessed using the MINI Suicidal Scale $(r=0.412, \mathrm{p}<0.05)$. However, the association between $\mathrm{ADHD}$ symptoms and the number of suicide attempts was not significant among patients with unipolar depression (Table 3).

Among patients with bipolar depression, different patterns of results emerged. Specifically, the association between ADHD symptoms and suicide risk was not significant. However, as shown in Table 4 , the number of suicide attempts was correlated with comorbid adult ADHD symptoms ( $\mathrm{r}=0.324, \mathrm{p}<0.01)$. Table 5 presents the results of hierarchical regression anal-

Table 1. Sociodemographic comparison of unipolar depression and bipolar depression groups (\%)

\begin{tabular}{|c|c|c|c|c|}
\hline & Unipolar depression $(\mathrm{N}=37)$ & Bipolar depression $(\mathrm{N}=63)$ & $t / \chi^{2}$ & p-value \\
\hline Age (years) & $20.5 \pm 1.6$ & $20.5 \pm 1.7$ & -0.011 & 0.680 \\
\hline BMI & $24.4 \pm 4.6$ & $23.5 \pm 4.4$ & 0.986 & 0.327 \\
\hline \multicolumn{5}{|l|}{ Sex } \\
\hline Male & $37(100)$ & $63(100)$ & & \\
\hline Education (years) & $12.4 \pm 0.6$ & $12.4 \pm 0.8$ & 0.263 & 0.793 \\
\hline Family structure & & & 1.963 & 0.161 \\
\hline Living with both parents & $29(78.4)$ & $41(65.1)$ & & \\
\hline Others & $8(21.7)$ & $22(34.9)$ & & \\
\hline Perceived socioeconomic status & & & 1.949 & 0.377 \\
\hline High & $2(5.4)$ & $3(5.0)$ & & \\
\hline Middle & $28(75.7)$ & $40(63.5)$ & & \\
\hline
\end{tabular}

BMl: body mass index

Table 2. Comparison of psychological variables between unipolar depression and bipolar depression groups

\begin{tabular}{|c|c|c|c|c|}
\hline & Unipolar depression $(\mathrm{N}=37)$ & Bipolar depression $(\mathrm{N}=63)$ & $t / \chi^{2}$ & p-value \\
\hline Total PHQ-9 score & $19.1 \pm 4.8$ & $18.3 \pm 5.3$ & 0.678 & 0.912 \\
\hline Total CAARSK-SV score & $76.3 \pm 9.1$ & $78.5 \pm 9.4$ & -1.122 & 0.265 \\
\hline MINI Suicidal Scale & $12.7 \pm 8.7$ & $15.5 \pm 9.3$ & -1.497 & 0.138 \\
\hline Number of suicide attempts & $0.81 \pm 1.4$ & $1.41 \pm 1.6$ & -1.901 & 0.060 \\
\hline History of suicide attempts & & & 2.928 & 0.087 \\
\hline Yes & $17(45.9)$ & $40(63.5)$ & & \\
\hline No & $20(54.1)$ & $23(36.5)$ & & \\
\hline
\end{tabular}

CAARSK-SV: Conners Adult ADHD Rating Scale-Korean short version, MINI: Mini International Neuropsychiatric Interview, PHQ-9: Patient Health Questionnaire-9 
ysis for participants with bipolar depression. In model 1, two control variables, namely, BMI and educational level, emerged as significant predictors of the number of suicide attempts. In model 2, the CAARSK-SV scores significantly predicted the number of suicide attempts, when BMI, educational level, SES, and family structure were controlled for $(\beta=0.249, \mathrm{p}<0.05)$.

\section{DISCUSSION}

In this study, we examined the association between the severity of suicide risk and comorbid ADHD symptoms among male young adults with unipolar and bipolar depression. The association between ADHD symptom levels and the number of suicide attempts was significant among patients with bipolar depression but not among those with unipolar depression.

This result is similar to past findings. Specifically, although the sample was not limited to those with bipolar depression, adult patients with BPD who obtained higher scores on the ASRS were more likely to report a higher number of suicide attempts [24]. Further, the number of suicide attempts has been found to be higher among patients with ADHD symptoms and BPD than among those with only BPD (3\% vs. $1.1 \%)$ [25].

It is noteworthy that the association between the number of suicide attempts and ADHD symptoms was observed among patients with bipolar depression. Among those with unipolar depression, only the correlation between ADHD symptoms and suicide risk was significant. This result is comparable to the findings of Conejero et al.'s [26] study in which the association between ADHD status and the number of suicide attempts was moderated by mood disorders. This association is attributable to the sharedness of the trait of impulsivity between patients with ADHD and suicide attempters, which is underscored by the results of a prospective followup study [27]. In addition, common genetic factors, especially

Table 3. Bivariate associations between psychological variables and number of suicide attempts among unipolar depression ( $\mathrm{N}=37$ )

\begin{tabular}{lccc}
\hline & Number of suicide attempts & PHQ-9 & CAARSK-SV \\
\hline Number of suicide attempts & 1 & & \\
PHQ-9 & 0.240 & 1 & 1 \\
CAARSK-SV & 0.136 & $0.430^{* *}$ & $0.412^{*}$ \\
MINI Suicidal Scale & $0.582^{* *}$ & $0.609^{* *}$ & 1 \\
\hline
\end{tabular}

${ }^{*} \mathrm{p}<0.05,{ }^{* *} \mathrm{p}<0.01$. CAARSK-SV: Conners Adult ADHD Rating Scale-Korean short version, MINI: Mini International Neuropsychiatric Interview, PHQ-9: Patient Health Questionnaire-9

Table 4. Bivariate associations between psychological variables and number of suicide attempts among bipolar depression ( $\mathrm{N}=63$ )

\begin{tabular}{lccc}
\hline & Number of suicide attempts & PHQ-9 & CAARSK-SV \\
\hline Number of suicide attempts & 1 & & \\
PHQ-9 & $0.309^{*}$ & 1 & 1 \\
CAARSK-SV & $0.324^{* *}$ & $0.466^{* *}$ & 0.172 \\
MINI Suicidal Scale & $0.541^{* *}$ & $0.291^{*}$ & 1 \\
\hline
\end{tabular}

${ }^{*} \mathrm{p}<0.05,{ }^{*} \mathrm{p}<0.01$. CAARSK-SV: Conners Adult ADHD Rating Scale-Korean short version, MINI: Mini International Neuropsychiatric Interview, PHQ-9: Patient Health Questionnaire-9

Table 5. Hierarchical regression analysis predicting number of suicide attempts using control variables and ADHD symptom score in patients with bipolar depression $(\mathrm{N}=63)$

\begin{tabular}{|c|c|c|c|c|c|c|}
\hline & B & SE & $\beta$ & t value & $\mathrm{p}$ value & Adjusted $\mathrm{R}^{2}$ \\
\hline \multicolumn{7}{|l|}{ Model 1} \\
\hline BMI & 0.095 & 0.045 & 0.260 & 2.117 & 0.039 & \multirow{4}{*}{$0.098^{*}$} \\
\hline Education & -0.645 & 0.258 & -0.316 & -2.512 & 0.015 & \\
\hline SES & 0.556 & 0.542 & 0.187 & 10.26 & 0.309 & \\
\hline Family structure & 0.719 & 0.611 & 0.213 & 1.178 & 0.244 & \\
\hline \multicolumn{7}{|l|}{ Model 2} \\
\hline $\mathrm{BMI}$ & 0.088 & 0.044 & 0.241 & 2.010 & 0.049 & \multirow{5}{*}{$0.145^{*}$} \\
\hline Education & -0.538 & 0.257 & -0.262 & -2.091 & 0.041 & \\
\hline SES & 0.426 & 0.532 & 0.143 & 0.802 & 0.426 & \\
\hline Family structure & 0.575 & 0.598 & 0.170 & 0.961 & 0.341 & \\
\hline ADHD score & 0.043 & 0.021 & 0.249 & 2.056 & $0.044^{*}$ & \\
\hline
\end{tabular}

${ }^{*} p<0.05$. ADHD: attention-deficit/hyperactivity disorder, B: unstandardized regression coefficients, BMl: body mass index, SE: standard error, SES: perceived socioeconomic status, $\beta$ : standardized regression coefficients 
those that are related to impulsivity, may explain the independent association between suicidal behaviors and ADHD symptoms [28]. Therefore, since underlying ADHD symptoms are associated with suicide risk, we speculate that ADHD patients who also had bipolar depression may have been more vulnerable to suicide attempts.

Recent meta-analytic findings suggest that the rate of suicide attempts does not differ significantly between patients with unipolar and bipolar depression [29]. Similarly, in this study, there was no significant difference in the sociodemographic and clinical characteristics of the two groups (e.g., the severity of depressive symptoms, ADHD symptom levels, the number of suicide attempts, the severity of suicide risk). In this regard, our findings have clinical implications because they suggest that patients who experience depressive episodes, bipolarity, and ADHD symptoms are at greater risk for suicide behaviors, which are life threatening.

Our findings are comparable to Wang et al.'s [30] observations. Though the study was conducted among nonclinical young adults in South Korea, they observed trends that were indicative of a stronger history of suicidality and greater severity of depression among participants with both MDQ and Wender Utah Rating Scale positivity. Few past studies have focused on Korean adult mood disorder patients with ADHD symptoms, and no past study has delineated the association between ADHD symptoms and suicidal behaviors using a homogeneous group of patients with bipolar depression.

This study has several limitations. First, the retrospective self-report questionnaires that were used in this study may have resulted in recall biases and underreporting or overreporting. Moreover, only male young adults were included in the sample. Therefore, caution must be exercised when these results are generalized to the larger population. Finally, the cross-sectional design of this study does not permit us to draw inferences about the causality of the emergent relationships. The mechanisms that underlie the effect of the comorbidity of ADHD symptoms on suicidality and ADHD management on the progress and prognosis of mood disorders should be examined in future long-term cohort studies.

This is the first study to have found that there is an association between ADHD symptoms and the number of suicide attempts among those with bipolar depression but not among those with unipolar depression. It is challenging to treat patients with BPD who are currently experiencing a depressive episode, and the evaluation of bipolarity is clinically essential. The assessment of ADHD symptoms in patients with mood disorders is also important, but medical practitioners tend to have a low index of suspicion for ADHD in such individuals. When a patient is suspected to have bipolar depression, additional assessment of ADHD symptoms and their sever- ity should be undertaken, even if he or she is a young adult and especially if he or she is at high risk for suicide. More comprehensive treatment plans that are developed based on the results of thorough evaluations will improve clinical outcomes and prognosis.

\section{CONCLUSION}

The association between ADHD symptom levels and the number of suicide attempts was significant among patients with bipolar depression. The findings underscore the importance of screening and assessing ADHD symptoms in male young adults with mood disorders.

\section{Acknowledgments}

None.

\section{Conflicts of Interest}

The authors have no potential conflicts of interest to disclose.

\section{Author Contributions}

Conceptualization: Chan-Mo Yang, Bung-Nyun Kim. Data curation: Chan-Mo Yang. Formal analysis: Chan-Mo Yang. Funding acquisition: Bung-Nyun Kim. Investigation: Chan-Mo Yang. Methodology: ChanMo Yang, Bung-Nyun Kim. Project administration: Bung-Nyun Kim. Resources: Bung-Nyun Kim. Software: Chan-Mo Yang. Supervision: Bung-Nyun Kim. Validation: Bung-Nyun Kim. Visualization: Chan-Mo Yang. Writing_original draft: Chan-Mo Yang. Writing_review \& editing: Bung-Nyun Kim.

\section{ORCID iDs}

Chan-Mo Yang https://orcid.org/0000-0002-4959-7595

Bung-Nyun Kim https://orcid.org/0000-0002-2403-3291

\section{REFERENCES}

1) Fayyad J, Sampson NA, Hwang I, Adamowski T, Aguilar-Gaxiola S, Al-Hamzawi A, et al. The descriptive epidemiology of DSM-IV Adult ADHD in the World Health Organization World Mental Health Surveys. Atten Defic Hyperact Disord 2017;9:47-65.

2) Faraone SV, Biederman J, Mick E. The age-dependent decline of attention deficit hyperactivity disorder: a meta-analysis of followup studies. Psychol Med 2006;36:159-165.

3) Kessler RC, Adler L, Barkley R, Biederman J, Conners CK, Demler $\mathrm{O}$, et al. The prevalence and correlates of adult ADHD in the United States: results from the National Comorbidity Survey Replication. Am J Psychiatry 2006;163:716-723.

4) Ginsberg Y, Quintero J, Anand E, Casillas M, Upadhyaya HP. Underdiagnosis of attention-deficit/hyperactivity disorder in adult patients: a review of the literature. Prim Care Companion CNS Disord 2014;16:PCC.13r01600.

5) Karlsdotter K, Bushe C, Hakkaart L, Sobanski E, Kan CC, Lebrec $\mathrm{J}$, et al. Burden of illness and health care resource utilization in adult psychiatric outpatients with attention-deficit/hyperactivity disorder in Europe. Curr Med Res Opin 2016;32:1547-1556.

6) Trollor JN. Attention deficit hyperactivity disorder in adults: conceptual and clinical issues. Med J Aust 1999;171:421-425.

7) Halmøy A, Fasmer OB, Gillberg C, Haavik J. Occupational outcome in adult ADHD: impact of symptom profile, comorbid psychiatric problems, and treatment: a cross-sectional study of 414 clinically diagnosed adult ADHD patients. J Atten Disord 2009; 
13:175-187.

8) Cumyn L, French L, Hechtman L. Comorbidity in adults with attention-deficit hyperactivity disorder. Can J Psychiatry 2009;54: 673-683.

9) Biederman J, Faraone SV, Spencer T, Wilens T, Norman D, Lapey KA, et al. Patterns of psychiatric comorbidity, cognition, and psychosocial functioning in adults with attention deficit hyperactivity disorder. Am J Psychiatry 1993;150:1792-1798.

10) Lee MJ, Yang KC, Shyu YC, Yuan SS, Yang CJ, Lee SY, et al. Attention-deficit hyperactivity disorder, its treatment with medication and the probability of developing a depressive disorder: a nationwide population-based study in Taiwan. J Affect Disord 2016;189: 110-117.

11) Biederman J, Ball SW, Monuteaux MC, Mick E, Spencer TJ, McCreary M, et al. New insights into the comorbidity between ADHD and major depression in adolescent and young adult females. J Am Acad Child Adolesc Psychiatry 2008;47:426-434.

12) Nierenberg AA, Miyahara S, Spencer T, Wisniewski SR, Otto MW, Simon N, et al. Clinical and diagnostic implications of lifetime attention-deficit/hyperactivity disorder comorbidity in adults with bipolar disorder: data from the first 1000 STEP-BD participants. Biol Psychiatry 2005;57:1467-1473.

13) Torres I, Garriga M, Sole B, Bonnín CM, Corrales M, Jiménez E, et al. Functional impairment in adult bipolar disorder with ADHD. J Affect Disord 2018;227:117-125.

14) Stickley A, Koyanagi A, Ruchkin V, Kamio Y. Attention-deficit/hyperactivity disorder symptoms and suicide ideation and attempts: findings from the Adult Psychiatric Morbidity Survey 2007. J Affect Disord 2016;189:321-328.

15) Impey M, Heun R. Completed suicide, ideation and attempt in attention deficit hyperactivity disorder. Acta Psychiatr Scand 2012; 125:93-102.

16) Jon DI, Hong N, Yoon BH, Jung HY, Ha K, Shin YC, Bahk WM. Validity and reliability of the Korean version of the Mood Disorder Questionnaire. Compr Psychiatry 2009;50:286-291.

17) Kessler RC, Adler L, Ames M, Demler O, Faraone S, Hiripi E, et al. The World Health Organization Adult ADHD Self-Report Scale (ASRS): a short screening scale for use in the general population. Psychol Med 2005;35:245-256.

18) Han C, Jo SA, Kwak JH, Pae CU, Steffens D, Jo I, et al. Validation of the Patient Health Questionnaire-9 Korean version in the elderly population: the Ansan Geriatric study. Compr Psychiatry 2008; 49:218-223

19) Hirschfeld RM, Williams JB, Spitzer RL, Calabrese JR, Flynn L,
Keck PE Jr, et al. Development and validation of a screening instrument for bipolar spectrum disorder: the Mood Disorder Questionnaire. Am J Psychiatry 2000;157:1873-1875.

20) Kim JH, Lee EH, Joung YS. The WHO Adult ADHD Self-Report Scale: reliability and validity of the Korean version. Psychiatry Investig 2013;10:41-46.

21) Conners CK, Erhardt D, Sparrow EP. Conners' adult ADHD rating scales (CAARS): technical manual. North Tonawanda, NY: Multi-Health Systems Inc. (MHS);1999.

22) Chang MS. The validation of Conners' Adult ADHD Scale-Korean (short version). Korean J Clin Psychol 2008;27:499-513.

23) Sheehan DV, Lecrubier Y, Sheehan KH, Amorim P, Janavs J, Weiller E, et al. The Mini-International Neuropsychiatric Interview (M.I.N.I.): the development and validation of a structured diagnostic psychiatric interview for DSM-IV and ICD-10. J Clin Psychiatry 1998;59 Suppl 20:22-33.

24) Pinna M, Visioli C, Rago CM, Manchia M, Tondo L, Baldessarini RJ. Attention deficit-hyperactivity disorder in adult bipolar disorder patients. J Affect Disord 2019;243:391-396.

25) Lan WH, Bai YM, Hsu JW, Huang KL, Su TP, Li CT, et al. Comorbidity of ADHD and suicide attempts among adolescents and young adults with bipolar disorder: a nationwide longitudinal study. J Affect Disord 2015;176:171-175.

26) Conejero I, Jaussent I, Lopez R, Guillaume S, Olié E, Hebbache C, et al. Association of symptoms of attention deficit-hyperactivity disorder and impulsive-aggression with severity of suicidal behavior in adult attempters. Sci Rep 2019;9:4593.

27) Chen MH, Chen YS, Hsu JW, Huang KL, Li CT, Lin WC, et al. Comorbidity of ADHD and subsequent bipolar disorder among adolescents and young adults with major depression: a nationwide longitudinal study. Bipolar Disord 2015;17:315-322.

28) Ljung T, Chen Q, Lichtenstein P, Larsson H. Common etiological factors of attention-deficit/hyperactivity disorder and suicidal behavior: a population-based study in Sweden. JAMA Psychiatry 2014;71:958-964

29) Shan P, Hu L, Xu D, Fang C, Li J, Jiang D, et al. Difference in the prevalence of non-fatal suicidal behaviours in patients with unipolar and bipolar depression in China: a meta-analysis. Oncotarget 2018;9:35493-35499.

30) Wang HR, Jung YE, Chung SK, Hong J, Ri Kang N, Kim MD, et al. Prevalence and correlates of bipolar spectrum disorder comorbid with ADHD features in nonclinical young adults. J Affect Disord 2017;207:175-180. 